\title{
Taguchi Robust Design for Optimizing Surface Roughness of Turned AISI 1045 Steel Considering the Tool Nose Radius and Coolant as Noise Factors
}

\author{
Adel T. Abbas $\mathbb{D}^{1},{ }^{1}$ Adham E. Ragab $\mathbb{D}^{2},{ }^{2}$ Faycal Benyahia, ${ }^{1}$ and Mahmoud S. Soliman $\mathbb{D}^{1}$ \\ ${ }^{1}$ Department of Mechanical Engineering, College of Engineering, King Saud University, P.O. Box 800, Riyadh 11421, \\ Saudi Arabia \\ ${ }^{2}$ Department of Industrial Engineering, College of Engineering, King Saud University, P.O. Box 800, Riyadh 11421, Saudi Arabia
}

Correspondence should be addressed to Adel T. Abbas; aabbas@ksu.edu.sa

Received 6 June 2018; Revised 20 September 2018; Accepted 22 October 2018; Published 11 November 2018

Academic Editor: Fernando Lusquiños

Copyright (C) 2018 Adel T. Abbas et al. This is an open access article distributed under the Creative Commons Attribution License, which permits unrestricted use, distribution, and reproduction in any medium, provided the original work is properly cited.

\begin{abstract}
AISI 1045 has been widely used in many industrial applications requiring good wear resistance and strength. Surface roughness of produced components is a vital quality measure. A suitable combination of machining process parameters must be selected to guarantee the required roughness values. The appropriate parameters are generally defined based on ideal lab conditions since most of the researchers conduct their experiments in closed labs and ideal conditions. However, when repeating these experiments in industrial workshops, different results are obtained. Imperfect conditions such as the absence of a turning tool with definite specifications as shown in know-how "tool nose radius $0.4 \mathrm{~mm}$ " and its replacement with the closest existence tool "tool nose radius $0.8 \mathrm{~mm}$ " as well as the interruption of cutting fluid during work as a result of sudden failure in the coolant pump lead to the mentioned different lab-industrial conditions. These complications are common among normal problems that happened during the metal cutting process in realistic conditions and are called noise factors. In this paper, Taguchi robust design is used to select the optimum combination of the cutting speed, depth of cut, and feed rate to enhance the surface roughness of turned AISI 1045 steel bars while minimizing the effects of the two noise factors. The optimum parameters predicted by the developed model showed good agreement with the experimental results.
\end{abstract}

\section{Introduction}

For its attractive characteristics from a stand point of view of machinability, strength, wear resistance, and impact properties, AISI 1045 steel is widely used in diverse industrial applications. Several widely used machine components are made of this material such as shafts, gears, crankshafts, connecting rods, bolts, and others. Considerable researchers investigated the effect of processing parameters on the final machining quality represented by the surface roughness of the machined products made of different materials such as AISI 1045 steel, AISI 1015, and AL 6063.

Deepak and Rajendra [1] carried out an analysis of the effect of the process parameters, such us feed rate, cutting speed, and depth of cut, on machined product surface roughness. Using Taguchi robust design method, they found that the order of the most influential process parameters on the surface roughness is the feed rate then the cutting speed followed by the depth of cut.

Zhang et al. [2] worked on the optimization of the surface quality obtained in CNC milling operation using the Taguchi method. An orthogonal array L9 (34) was adapted for the design of experiment of the study whose results were analyzed using ANOVA. The main control factors of the study were the spindle speed, feed rate, and depth of cut, while the chamber temperature and different tool inserts (condition and dimensional variability) were considered noise factors of the study. The ANOVA analyses looking for the optimum surface roughness and signal-to-noise ratio confirmed the test verified factors significant optimum for the best response. 
Qasim et al. [3] studied the optimization of processing parameters using several cutting tools. The focus was on the reduction of cutting forces and generated temperature during the cutting process of AISI 1045 steel material. The main parameters considered in this study are the feed rate, cutting speed, depth of cut, and rake angle in the orthogonal machining process. Different analysis techniques have been combined in this investigation, namely, the signal-to-noise ratio, the Taguchi matrix, the analysis of variance (ANOVA), and the finite element simulation. The latter was conducted using the commercial FEA software, ABAQUS, whereas the statistical study was conducted with Minitab package. The analysis concluded that the depth of cut and the feed rate are the most influential on the cutting force and hence should be considered for its optimization. Nevertheless, the cutting speed and rake angle are demonstrated to be the most significant on the optimum resulting cutting temperature. Moreover, the study concluded that, for machining AISI 1045, carbide cutting tools provide lower cutting forces and temperatures compared than uncoated cemented carbide tools.

Bhattacharya et al. [4] conducted an experimental investigation, driven by Taguchi techniques, on the effects of cutting parameters on the surface finish and processing power consumption. Processing of AISI 1045 steel at high speed using coated carbide tools was also studied by the authors. The analysis of variance and orthogonal array were used to determine the contribution of the cutting speed, feed rate, depth of cut on the surface roughness, and power consumption. The cutting speed was found to be the only significant parameter on the surface finish and power consumption.

Moganapriya et al. [5] conducted an experimental study on the effects of processing parameters on the quality of CNC turning of AISI 1015 mild steel. The objective was to minimize the surface roughness while maximizing the material removal rate. An optimization has been conducted using the Taguchi method with an L9 orthogonal array related to the tool coating material (TiAlN/WC-C, TiAlN), depth of cut, feed rate, and spindle speed as input parameters and targeting to maximize the material removal rate for efficiency and the minimization of surface roughness for quality. The authors established a predictive correlation for determining the material removal rate and surface roughness for a given set of parameters. The optimal machining conditions were identified for a cutting speed of $600 \mathrm{~m} / \mathrm{min}$, a medium depth of cut of $1.5 \mathrm{~mm}$, a high feed rate of $0.15 \mathrm{~mm} / \mathrm{rev}$, and a multilayer deposition from the selected levels. Good agreement between experimental tests and prediction values of surface roughness and material removal rate were reported.

Mazarbhuiya et al. [6] searched the optimal processing factors of the electric discharge machining of an aluminum part using a copper tool electrode. Discharge current, flushing pressure, polarity, and the pulse ON time were the main input parameters of the study. Two main machining responses were targeted: the material removal rate and the surface roughness. The experiments were designed based on the Taguchi method, and the results were analyzed using
ANOVA method. The best operating conditions based on large-the-better were reported for a discharge current of $16 \mathrm{~A}$, a pulse ON time of $463 \mu \mathrm{s}$, a flushing pressure of $10 \mathrm{kgf} / \mathrm{cm}^{2}$, and a normal polarity. Likewise, the best operating conditions providing an optimum surface roughness based on smaller-the-best approach were reported for a discharge current of $8 \mathrm{~A}$, a pulse $\mathrm{ON}$ time of $463 \mu \mathrm{s}$, a reverse polarity, and flushing pressure of $10 \mathrm{kgf} / \mathrm{cm}^{2}$. The obtained optimal settings were validated by $\mathrm{S} / \mathrm{N}$ ratio and the generated average performance graph. Besides, the analysis showed that, for the material removal rate, the polarity is the most affecting parameter followed by the current level whereas the surface roughness is found to be only affected by the current level.

Manivel and Gandhinathan [7] studied the optimization of the cutting parameters in hard turning of ADI by carbide inserts CVD coated with $\mathrm{Al}_{2} \mathrm{O}_{3}$ /MT TICN. Based on the Taguchi method, dry conditions experiments have been designed using an L18 orthogonal array taking the cutting speed, the feed rate, the depth of cut, and the nose radius as the independent input parameters. Two levels of the nose radius and three levels of all other parameters were considered in the study while all other parameters were considered constant. The ANOVA, signal-to-noise ratio, and regression analyses were used to optimize the processing parameters. The study confirms that the cutting speed is the most influential parameter on the surface roughness and the tool wear. The predicted optimum cutting parameters were verified through experimental tests where surface roughness and tool wear are found closer to $9.27 \%$ and $1.05 \%$ of deviations, respectively.

Nalbant et al. [8] conducted an experimental study aiming to explore the effect of turning operations parameters on the surface roughness of AISI 1030 carbon steel material. The insert radius and feed rate parameters were found to have a higher impact of the surface roughness compared to that of the depth of cut parameter. Taguchi's robust design method was used to prepare the experimental plan of experience and to analyze the obtained results. The obtained optimum results obtained with the Taguchi method were validated experimentally confirming the validity of the drawn conclusions.

Asiltürk and Akkuş [9] investigated the effect of cutting speed, feed rate, and depth of cut on the resultant surface roughness during CNC turning operations. Nonlubricated tests were conducted on AISI 4140 (51 HRC) material samples using coated carbide cutting tools. A new cutting insert was used for each test for accurate reading. Also, tests were repeated three times each for better confidence. The analysis of the results using ANOVA and signal-to-noise ratio highlighted the dominance of the feed rate effect on the surface roughness. Moreover, the interaction of the feed rate speed and depth of cut was found to play an important role on machining surface quality.

Hwang and Lee [10] searched the minimum quantity lubrication as well as the wet turning of AISI 1045 material in the perspective of developing a model capable of predicting the cutting force along with the surface roughness for a given set of processing parameters. The experiments were designed 
based on a fractional factorial and a central composite design. The surface roughness and cutting force were measured through the external cylindrical turning surface according to the machining factors used in the established plan of experiments. Optimal cutting parameters were determined from the developed experimental relationships.

Abbas et al. [11] conducted a multiobjective optimization research of the processing factors in turning a heattreated alloy steel material (J-steel) using uncoated tungstencarbide tools under unlubricated conditions. The study aimed at finding the adequate settings of the cutting parameters (cutting speed, depth of cut, and feed rate) leading to the optimum response combination of the surface roughness and the material removal rate. The experimental study was conducted based on samples generated based on a five-level full factorial matrix. The analysis of the results identified a Pareto tradeoff frontier among the objectives and showed a "knee" shape for which some processing setting could reach both good surface finish and high material removal rate within certain limits. Beyond those limits, improving one of the objectives would be at the cost of the second objective.

Al Bahkali et al. [12] studied the effect of machining parameters (feed rate, cutting speed, depth of cut, and tool nose radius) on the surface roughness of cast iron material machined in a turning operation. Turning tools with carbide inserts and nose radii of 0.4 and $0.8 \mathrm{~mm}$ were sued. The surface roughness was measured for each set of machining factors. A design of experiment based on three levels of each of the input parameters was implemented to establish a model relating the machining factors to the resulting surface finish. The results revealed that the tool nose and feed rate are the most affecting parameters on the surface roughness of the machined product. The cutting speed and the depth of cut are shown of lower influence. The lowest roughness was obtained at the lowest feed rate, the highest cutting speed, and the lowest depth of cut for higher nose radius. A multiobjective optimization was also driven to measure the process productivity aiming at maximizing the material removal rate and minimize the surface roughness simultaneously. Also a close look to the surface finish under optical microscopy showed that, for the lower nose radius $(0.4 \mathrm{~mm})$, there are higher chances of graphite pullouts that deteriorated the surface roughness.

In this paper, Taguchi robust design is used to evaluate the effect of two noise factors (tool nose radius and coolant status) on the surface roughness of turned AISI 1045 steel bars for different levels of cutting speeds, depth of cut, and feed rate. Both of the noise factors are given two levels while the processing parameters range is divided into three levels each.

\section{Materials and Methods}

2.1. Materials and Testing. The chemical composition of studied AISI 1045 steel, as measured by spectroscopic analysis, is shown in Table 1. This material was heat treated such that it was heated to $840^{\circ} \mathrm{C}$, held until the temperature was uniform, and soaked for one hour and quenched in water
TABLE 1: Chemical composition of AISI 1045.

\begin{tabular}{lccccccc}
\hline $\mathrm{C}$ & $\mathrm{Mn}$ & $\mathrm{Si}$ & $\mathrm{Cu}$ & $\mathrm{Cr}$ & $\mathrm{Ni}$ & $\mathrm{S}$ & $\mathrm{Fe}$ \\
\hline 0.462 & 0.642 & 0.220 & 0.206 & 0.079 & 0.066 & 0.004 & Balance
\end{tabular}

to produce martensitic structure. The hardening stage was followed by tempering at $600^{\circ} \mathrm{C}$, holding until the temperature is uniform; soaking for two hours, and then cooling in still air. The hardness of tempered steel was in the range of $\mathrm{HV}$ 240-246. The procedure of heat treatment was suggested by steel manufacturer to have proper combination of strength and ductility for the tempered martensite. The average tensile strength and elongation\% (in $50 \mathrm{~mm}$ ) were $635 \mathrm{MPa}$ and 17 , respectively. A sample of $20 \mathrm{~mm}$ in diameter was prepared for the microstructure study using standard methods of grinding, polishing, and etching ( $2 \%$ nital), respectively. The microstructure was observed using Olympus optical microscope with the data base system and JOEL-SEM6600.

A CNC turning machine equipped with Sinumeric 840$\mathrm{D}$ was used to conduct all experiments. The drive power is equal $13 \mathrm{~kW}$. The uncoated tungsten carbide insert was clamped with the tool holder to carry out this work. The tool holder specification is SDJCL $2020 \mathrm{~K} 11$ while the two inserts specifications are DCMT 11 T3 04-KM H13A and DCMT $11 \mathrm{~T} 308-\mathrm{KM} \mathrm{H} 13 \mathrm{~A}$. The clearance and cutting edge angles are $7^{\circ}$ and $55^{\circ}$, respectively. The tool nose radiuses are $0.4 \mathrm{~mm}$ and $0.8 \mathrm{~mm}$, respectively. The test rig used for machining the specimens is shown in Figure 1.

The test specimens have an initial diameter of $50 \mathrm{~mm}$ and a length of $135 \mathrm{~mm}$. $30 \mathrm{~mm}$ will be used for the chuck clamping, $10 \mathrm{~mm}$ for clearance grooving, and $75 \mathrm{~mm}$ will be used for applying the test experiment. A standard conical center was created from the other side for supporting the rotary center of the tail stock. The test specimen drawing is shown in Figure 2.

A total of 108 tests were conducted. This test assembly was divided into four different equal groups based on the cutting tool nose radius $(0.4 \mathrm{~mm} / 0.8 \mathrm{~mm})$ and on the cutting condition (wet/dry). Each of the resultant subassemblies formed of 27 tests was divided into three main groups of 9 tests each machined using three different surface speeds: 150,125 , and $100 \mathrm{~meter} / \mathrm{min}$. The groups of the 9 tests were in their turn divided into three subgroups where each was subjected to a different level-depth cut of $0.75,0.5$, and $0.25 \mathrm{~mm}$. Each of the final subgroups, operated with one cut depth level, was machined using one of three different feed rates: $0.15,0.10$, and $0.05 \mathrm{~mm} / \mathrm{rev}$. The test rig for measuring the resultant surface roughness is shown in Figure 3.

2.2. Robust Design Optimization. Several factors affect the surface roughness produced during machining processes. Some of these factors are controllable during machining and hence called "control factors". Others are impossible or costly to control and are called "noise factors". Robust optimization aims at determining the combination of control factors' settings that minimize variations of the process output due to the existence of the noise factors. 


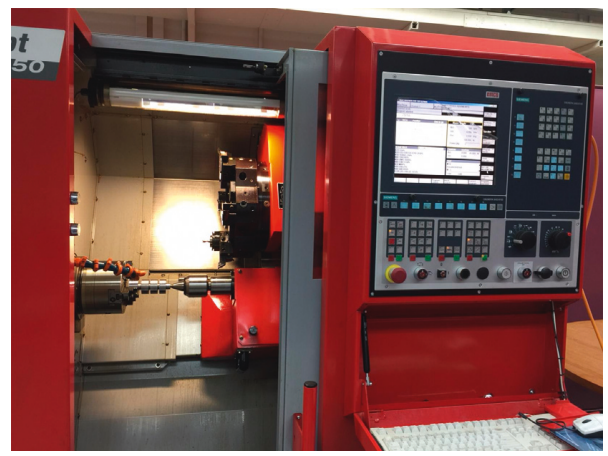

Figure 1: Test rig for machining specimens.

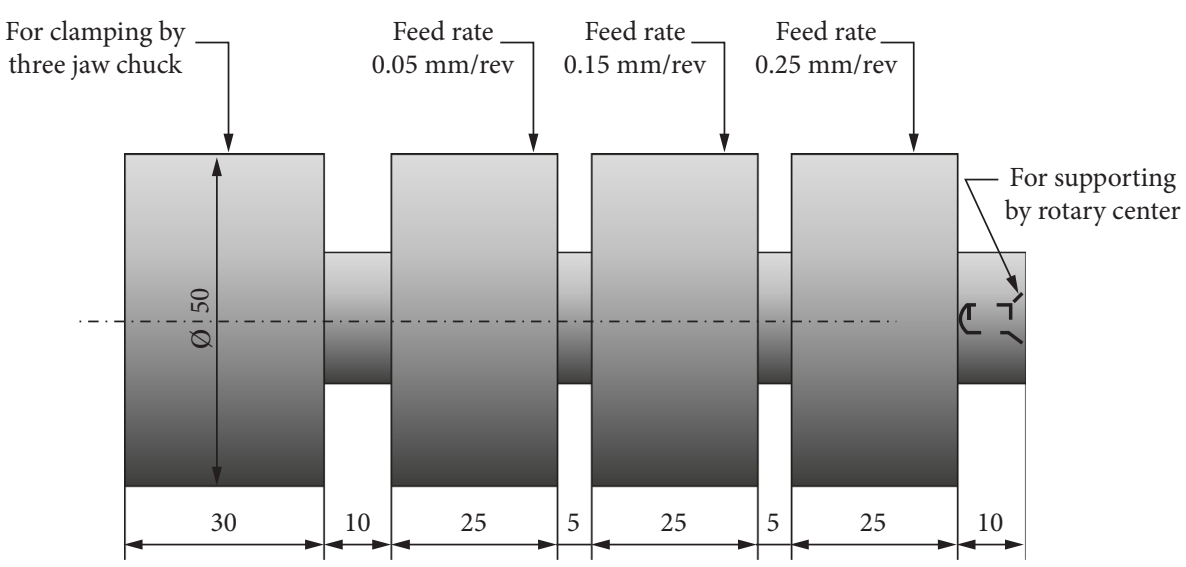

Figure 2: Test specimen drawing.

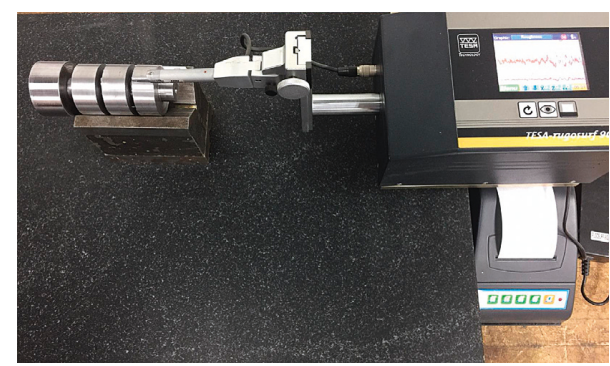

FIGURE 3: Test rig for measuring the specimen surface roughness.

2.2.1. Selection of Control Factors. The effect of three control factors, namely, cutting speed, depth of cut, and feed rate, on the produced surface roughness is investigated in this study. The considered range of each factor was divided into three levels as summarized in Table 2 .

2.2.2. Selection of Noise Factors. Two noise factors were investigated in this study, namely, the tool nose radius and coolant operation $\mathrm{ON} / \mathrm{OFF}$ status. These two factors affect the surface roughness of produced parts while controlling them during regular production is not always possible. For different reasons, workers in workshops may not follow precisely the selection of a particular nose radius. Also, if the coolant system is broken down or does not function properly, the machine operator will not necessarily turn off
TABle 2: The control factors and their levels used in the current study.

\begin{tabular}{lcccc}
\hline Designation & Process parameter & Level 1 & Level 2 & Level 3 \\
\hline$S$ & Cutting speed $(\mathrm{m} / \mathrm{min})$ & 100 & 125 & 150 \\
DOC & Depth of cut $(\mathrm{mm})$ & 0.25 & 0.5 & 0.75 \\
FR & Feed rate $(\mathrm{mm} / \mathrm{rev})$ & 0.05 & 0.10 & 0.15 \\
\hline
\end{tabular}

the machine. Two levels were selected for the tool nose radius (NR): 0.4 and $0.8 \mathrm{~mm}$, and two levels for coolant were selected: coolant $\mathrm{ON}$ and coolant OFF.

2.2.3. Orthogonal Array. Taguchi L27 orthogonal array was used in this study as the inner array that represents the control variables (3 factors, 3 levels each). L27 array can run up to 13 factors with 3 levels each. It provides 26 degrees of freedom allowing the calculation of several factors interaction effects if needed. L4 outer array was used to represent the noise factors ( 2 factors, 2 levels each.) The total number of runs was of 108 runs as illustrated in Table 3 along with the related measured surface roughness, $\mathrm{Ra}(\mu \mathrm{m})$.

\section{Results and Discussion}

A heat treatment of the as-received material has increased its hardness from range of $185-190 \mathrm{HV}$ to a value of $240-$ $246 \mathrm{HV}$ that improved the surface quality of the machined 
TABLE 3: Orthogonal array with the measured $\mathrm{Ra}(\mu \mathrm{m})$.

\begin{tabular}{|c|c|c|c|c|c|c|c|}
\hline \multicolumn{4}{|c|}{ Inner array } & \multicolumn{4}{|c|}{ Outer array } \\
\hline Test run & $\begin{array}{l}\text { Surface speed } \\
\quad(\mathrm{m} / \mathrm{min})\end{array}$ & $\begin{array}{l}\text { Depth of } \\
\text { cut }(\mathrm{mm})\end{array}$ & $\begin{array}{l}\text { Feed rate } \\
(\mathrm{mm} / \mathrm{rev})\end{array}$ & $\begin{array}{c}\mathrm{NR}=0.4 \\
\text { coolant: on }\end{array}$ & $\begin{array}{c}\mathrm{NR}=0.4 \\
\text { coolant: off }\end{array}$ & $\begin{array}{c}\mathrm{NR}=0.8 \\
\text { coolant: on }\end{array}$ & $\begin{array}{l}\mathrm{NR}=0.8 \\
\text { coolant: off }\end{array}$ \\
\hline L01 & 150 & 0.75 & 0.15 & 1.8317 & 1.970 & 1.181 & 1.654 \\
\hline L02 & 150 & 0.75 & 0.10 & 1.003 & 1.157 & 0.941 & 1.302 \\
\hline L03 & 150 & 0.75 & 0.05 & 0.411 & 0.855 & 0.547 & 0.783 \\
\hline L04 & 150 & 0.5 & 0.15 & 1.588 & 1.530 & 1.171 & 1.231 \\
\hline L05 & 150 & 0.5 & 0.10 & 1.019 & 1.337 & 0.734 & 1.109 \\
\hline L06 & 150 & 0.5 & 0.05 & 0.652 & 1.174 & 0.482 & 0.653 \\
\hline L07 & 150 & 0.25 & 0.15 & 1.072 & 1.539 & 1.146 & 1.484 \\
\hline L08 & 150 & 0.25 & 0.10 & 0.925 & 1.416 & 0.820 & 1.393 \\
\hline L09 & 150 & 0.25 & 0.05 & 0.758 & 1.310 & 0.684 & 1.062 \\
\hline L10 & 125 & 0.75 & 0.15 & 1.803 & 2.287 & 1.058 & 2.039 \\
\hline L11 & 125 & 0.75 & 0.10 & 0.836 & 1.291 & 0.721 & 1.621 \\
\hline L12 & 125 & 0.75 & 0.05 & 0.514 & 1.000 & 0.612 & 1.351 \\
\hline L13 & 125 & 0.5 & 0.15 & 1.513 & 1.663 & 1.294 & 1.689 \\
\hline L14 & 125 & 0.5 & 0.10 & 1.051 & 1.290 & 1.013 & 1.667 \\
\hline L15 & 125 & 0.5 & 0.05 & 0.781 & 1.163 & 0.679 & 1.294 \\
\hline L16 & 125 & 0.25 & 0.15 & 1.621 & 1.780 & 1.235 & 2.576 \\
\hline L17 & 125 & 0.25 & 0.10 & 1.250 & 1.362 & 1.004 & 2.214 \\
\hline L18 & 125 & 0.25 & 0.05 & 1.072 & 1.143 & 0.687 & 1.590 \\
\hline L19 & 100 & 0.75 & 0.15 & 1.948 & 2.053 & 1.309 & 2.128 \\
\hline L20 & 100 & 0.75 & 0.10 & 1.167 & 1.828 & 1.163 & 1.978 \\
\hline L21 & 100 & 0.75 & 0.05 & 1.100 & 1.350 & 0.838 & 1.763 \\
\hline L22 & 100 & 0.5 & 0.15 & 1.524 & 1.895 & 1.470 & 2.450 \\
\hline L23 & 100 & 0.5 & 0.10 & 1.450 & 1.695 & 1.301 & 2.226 \\
\hline L24 & 100 & 0.5 & 0.05 & 1.398 & 1.445 & 1.000 & 2.145 \\
\hline L25 & 100 & 0.25 & 0.15 & 1.840 & 2.702 & 2.294 & 3.082 \\
\hline L26 & 100 & 0.25 & 0.10 & 1.438 & 2.659 & 1.963 & 2.272 \\
\hline L27 & 100 & 0.25 & 0.05 & 0.847 & 2.243 & 1.867 & 1.984 \\
\hline
\end{tabular}

material. The increase of hardness has caused the material to become less ductile reducing its plastic flow capacity offering a better surface finish. A brittle interaction between a cutting tool and a low ductility workpiece induces a material separation during machining rather than a plastic flow causing surface irregularities.

It is well documented that the microstructure of annealed/normalized AISI 1045 is composed of ferrite and pearlite. The microstructure of tempered specimen is shown in Figure 4(a). It is composed of ferrite areas (white) and tempered martensite (dark). The dark area in the optical microstructure was enlarged using SEM as shown Figure 4(b). The ferrite appears as dark areas and carbides as white areas.

3.1. Signal-to-Noise Ratio. In Taguchi analysis, the signal-tonoise ratio $(S / N)$ refers to the ratio of the power of signal to the power of noise $[2,13]$. Maximizing the $S / N$ guarantees the minimum effects of noise on the measured output. It is calculated for three objective functions: "the nominal is best", "the smaller is better," and "the larger is better" as given in Equations (1)-(3), respectively [14].

$$
\begin{aligned}
& \frac{S}{N}=10 \log \frac{\bar{y}^{2}}{s_{y}^{2}}, \\
& \frac{S}{N}=-10 \log \frac{1}{n}\left(\sum y^{2}\right),
\end{aligned}
$$

$$
\frac{S}{N}=-10 \log \frac{1}{n}\left(\sum \frac{1}{y^{2}}\right) .
$$

where $\bar{y}$ is the average of the observed data, $n$ is the number of observations, and $s_{y}^{2}$ is the variance of $y . S / N$ for the surface roughness measure $\mathrm{Ra}$ is calculated using Equation (2) because smaller $\mathrm{Ra}$ is better. Table 4 shows the $S / N$ ratio for the L27 orthogonal inner array. From the table, it is found that L03 has the highest $S / N$ ratio and hence provides the best combination with the minimum effects of noise factors within the tested levels of control factors. Figure 5 shows the main effect plot of $S / N$ ratio with respect to the control variables and their levels. The results suggest that the $S / N$ ratio is more sensitive to the cutting speed and feed rate while the variation with the depth of cut is of lower sensitivity.

3.2. Analysis of Variance (ANOVA). ANOVA was conducted to test the significance of both control and noise factors. Table 5 illustrates the ANOVA results with $p$ value less than 0.05 being considered significant. Terms with $p$ values higher than 0.05 are removed from the model unless they are a part of significantly higher term. ANOVA results prove the significance of all factors in combination with some interactions of second and third order. The nose radius, while not significant as a linear term, is significant in combination of other factors as illustrated by the $p$ value of the 2-way and 3-way interactions. The adjusted R-squared 


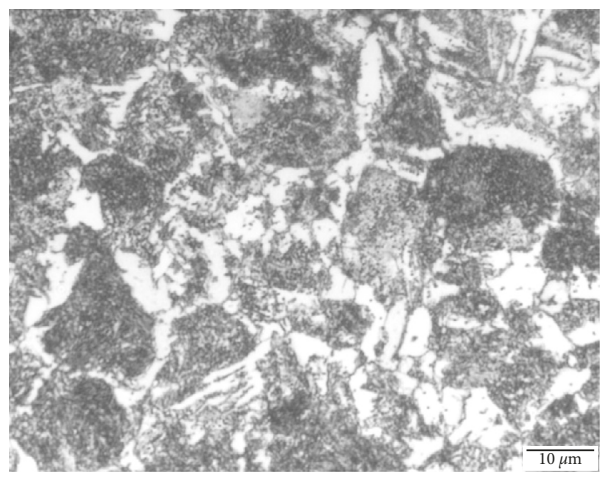

(a)

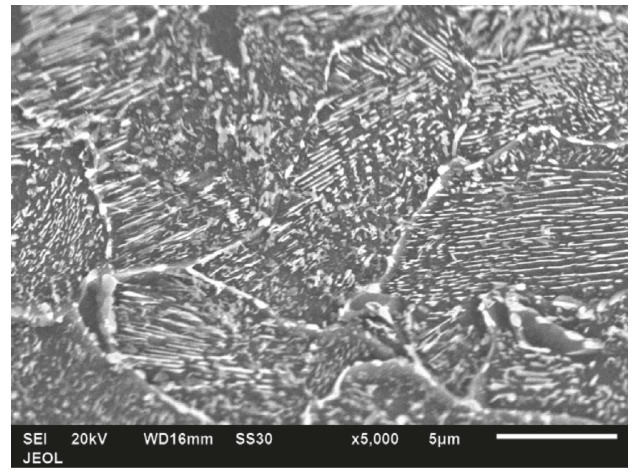

(b)

Figure 4: (a) Optical micrograph of tempered steel; it is composed of ferrite (white) and tempered martensite (dark). (b) Secondary electron image of the dark area in optical micrograph (tempered martensite) showing the presence of ferrite (dark areas) and carbides (white areas).

TABLE 4: $S / N$ ratio for the L27 orthogonal inner array.

\begin{tabular}{lccccc}
\hline$\#$ & $S / N$ & $\#$ & $S / N$ & $\#$ & $S / N$ \\
\hline L01 & -4.53567 & L10 & -5.36497 & L19 & -5.51797 \\
L02 & -0.90376 & L11 & -1.39333 & L20 & -3.96571 \\
L03 & 3.43843 & L12 & 0.62490 & L21 & -2.33181 \\
L04 & -2.87199 & L13 & -3.79391 & L22 & -5.46450 \\
L05 & -0.60185 & L14 & -2.15754 & L23 & -4.63266 \\
L06 & 2.10752 & L15 & -0.10513 & L24 & -3.82173 \\
L07 & -2.45098 & L16 & -5.42733 & L25 & -8.03586 \\
L08 & -1.36208 & L17 & -3.67699 & L26 & -6.56900 \\
L09 & 0.12517 & L18 & -1.34791 & L27 & -5.17539 \\
\hline
\end{tabular}

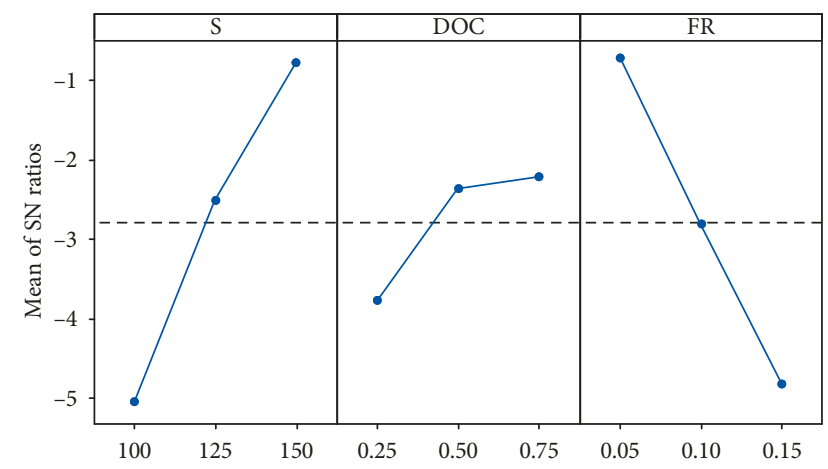

Signal-to-noise: Smaller is better

Figure 5: Main effect plot for $S / N$ ratio with respect to the control factors.

value is about $87 \%$ proving that the model is representative and explains $97 \%$ of the variation in measured outputs.

3.3. Regression and Optimization. In this paper, regression analysis is used to build a second-order relation between the response and control factors under different conditions of the L4 outer array. The goal is to investigate the significance of quadratic terms on the selection of optimum machining conditions to minimize the effect of noise factors. Table 6 summarizes the regression equations at the four combinations
TABLE 5: ANOVA results for control and noise factors.

\begin{tabular}{|c|c|c|c|c|c|}
\hline Source & $\mathrm{DF}$ & Adj. SS & Adj. MS & $F$ value & $p$ value \\
\hline Model & 31 & 28.7059 & 0.926 & 23.67 & 0 \\
\hline Linear & 8 & 24.6965 & 3.08706 & 78.92 & 0 \\
\hline$S$ & 2 & 8.2392 & 4.11961 & 105.32 & 0 \\
\hline DOC & 2 & 1.4196 & 0.70979 & 18.15 & 0 \\
\hline FR & 2 & 7.6466 & 3.82328 & 97.74 & 0 \\
\hline NR & 1 & 0.0015 & 0.00151 & 0.04 & 0.845 \\
\hline Coolant & 1 & 7.3896 & 7.38962 & 188.91 & 0 \\
\hline 2-way interactions & 17 & 3.1721 & 0.18659 & 4.77 & 0 \\
\hline$S * \mathrm{DOC}$ & 4 & 0.9537 & 0.23843 & 6.1 & 0 \\
\hline$S * \mathrm{NR}$ & 2 & 0.4967 & 0.24834 & 6.35 & 0.003 \\
\hline$S *$ coolant & 2 & 0.5287 & 0.26436 & 6.76 & 0.002 \\
\hline $\mathrm{DOC} * \mathrm{FR}$ & 4 & 0.4059 & 0.10147 & 2.59 & 0.043 \\
\hline $\mathrm{DOC} * \mathrm{NR}$ & 2 & 0.2202 & 0.11011 & 2.81 & 0.066 \\
\hline $\mathrm{FR} * \mathrm{NR}$ & 2 & 0.1385 & 0.06925 & 1.77 & 0.177 \\
\hline $\mathrm{NR} *$ coolant & 1 & 0.4284 & 0.42836 & 10.95 & 0.001 \\
\hline 3-way interactions & 6 & 0.8373 & 0.13955 & 3.57 & 0.004 \\
\hline$S * \mathrm{NR} *$ coolant & 2 & 0.3999 & 0.19993 & 5.11 & 0.008 \\
\hline $\mathrm{DOC} * \mathrm{FR} * \mathrm{NR}$ & 4 & 0.4374 & 0.10936 & 2.8 & 0.032 \\
\hline Error & 76 & 2.9728 & 0.03912 & & \\
\hline Total & 107 & \multicolumn{2}{|l|}{31.6787} & & \\
\hline$R$-sq & & \multicolumn{2}{|c|}{$R$-sq (adj.) } & \multicolumn{2}{|c|}{$R$-sq (pred.) } \\
\hline $90.62 \%$ & & \multicolumn{2}{|c|}{$86.79 \%$} & \multicolumn{2}{|c|}{$81.05 \%$} \\
\hline
\end{tabular}

of the outer array. The results show that the value of expected $\mathrm{Ra}$ depends on quadratic terms in some cases.

Composite desirability function was used to minimize the expected $\mathrm{Ra}$ in the calculated four regression equations. Table 7 shows the predicted optimum conditions for each equation and the corresponding expected $\mathrm{Ra}$. These cases were machined to validate the regression model output, and a comparison between the predicted and measured values are presented in the table.

Figure 6 represents the surface roughness profile produced by the surface roughness tester. It shows the increase of the feed rate and depth of cut were found to diminish the surface quality due the amount of forces and related friction involved in cutting larger material volume increments. Similar high speed rates and depth of cut effects have been reported by other studies $[11,12,15]$. 
TABLE 6: Regression equations at the four conditions of the L4 outer array.

\begin{tabular}{|c|c|}
\hline Outer array combination & Regression equation \\
\hline $\begin{array}{l}\mathrm{NR}=0.4 \\
\text { Coolant: on }\end{array}$ & $\mathrm{Ra}=1.949-0.00767 S-1.181 \mathrm{DOC}+2.34 \mathrm{FR}+11.34 \mathrm{DOC} * \mathrm{FR}$ \\
\hline $\begin{array}{l}\mathrm{NR}=0.4 \\
\text { Coolant: off }\end{array}$ & $\mathrm{Ra}=11.45-0.1197 S-8.36 \mathrm{DOC}+0.44 \mathrm{FR}+0.000373 S^{2}+3.17 \mathrm{DOC}^{2}+0.0279 S * \mathrm{DOC}+11.87 \mathrm{DOC} * \mathrm{FR}$ \\
\hline $\begin{array}{l}\mathrm{NR}=0.8 \\
\text { Coolant: on }\end{array}$ & $\mathrm{Ra}=10.63-0.1268 S-5.462 \mathrm{DOC}+5.291 \mathrm{FR}+0.000383 S^{2}+0.03777 \mathrm{~S} * \mathrm{DOC}$ \\
\hline $\begin{array}{l}\text { NR }=0.8 \\
\text { Coolant: off }\end{array}$ & $\mathrm{Ra}=4.654-0.02079 S-3.65 \mathrm{DOC}+6.342 \mathrm{FR}+2.98 \mathrm{DOC}^{2}$ \\
\hline
\end{tabular}

TABle 7: Optimum machining conditions at each noise-factor combination.

\begin{tabular}{lccccccccc}
\hline $\begin{array}{l}\text { Test } \\
\text { run }\end{array}$ & $\begin{array}{c}\text { Surface speed } \\
(\mathrm{m} / \mathrm{min})\end{array}$ & $\begin{array}{c}\text { Depth of } \\
\text { cut }(\mathrm{mm})\end{array}$ & $\begin{array}{c}\text { Feed rate } \\
(\mathrm{mm} / \mathrm{rev})\end{array}$ & $\begin{array}{c}\text { Tool nose } \\
\text { radius }(\mathrm{mm})\end{array}$ & Coolant & $\begin{array}{c}\text { Measured } \\
\mathrm{Ra}(\mu \mathrm{m})\end{array}$ & $\begin{array}{c}\text { Predicted } \\
\mathrm{Ra}(\mu \mathrm{m})\end{array}$ & $\begin{array}{c}(\%) \\
\text { Error }\end{array}$ & $\begin{array}{c}\text { Screen shot from } \\
\text { surface roughness tester }\end{array}$ \\
\hline 1 & 150 & 0.75 & 0.05 & 0.4 & On & 0.440 & 0.455 & 3 & Figure 6(a) \\
2 & 137 & 0.62 & 0.05 & 0.4 & Off & 0.866 & 0.848 & 2 & Figure 6(b) \\
3 & 150 & 0.25 & 0.05 & 0.8 & On & 0.552 & 0.541 & 2 & Figure 6(c) \\
4 & 150 & 0.64 & 0.05 & 0.8 & Off & 0.752 & 0.737 & 2 & Figure 6(d) \\
\hline
\end{tabular}

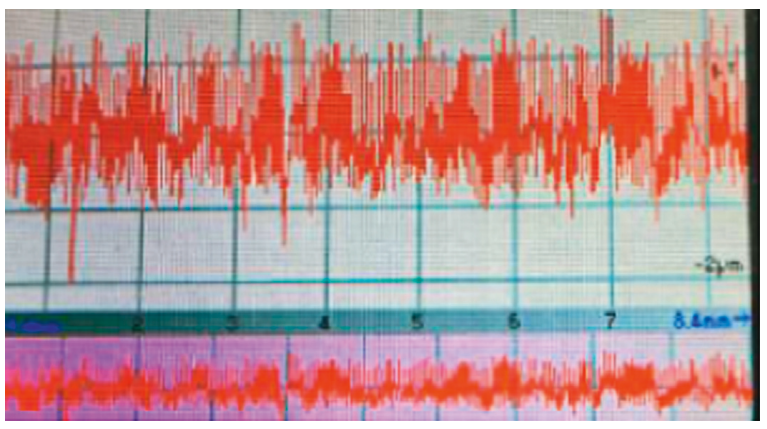

(a)

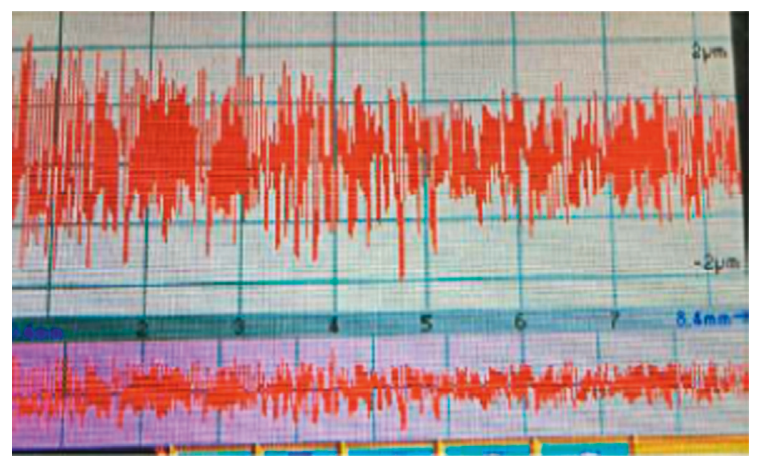

(c)

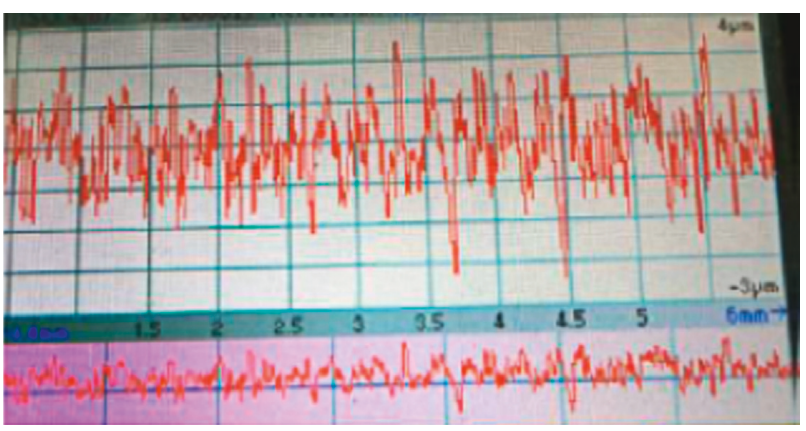

(b)

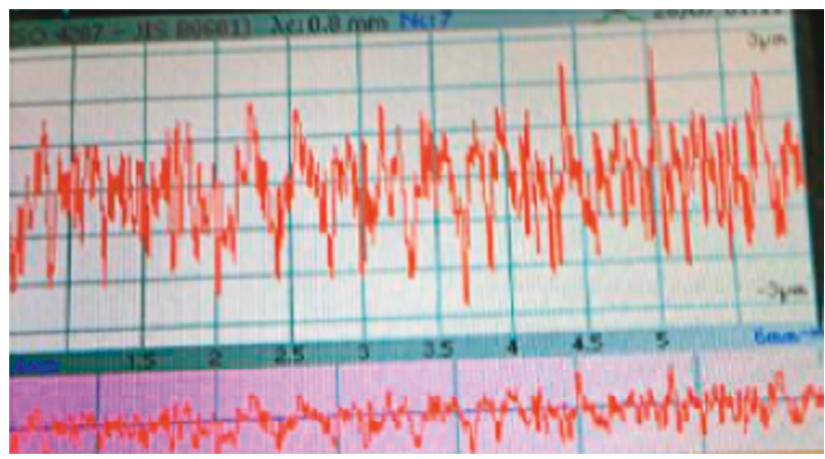

(d)

FiguRE 6: Screenshots from surface roughness tester for optimum machining conditions at each noise factors combination as shown in Table 7. (a) Test run-1; (b) test run-2; (c) test run-3; (d) test run-4.

Composite desirability function was used to select the optimum combination of control factors that optimizes $\mathrm{Ra}$ under different noise factors conditions, i.e., the control factors levels that will minimize the effects of the noise factors. This combination was: $\mathrm{S}=150 \mathrm{~m} / \mathrm{minute}$, DOC = $0.64 \mathrm{~mm}$, and $\mathrm{FR}=0.05 \mathrm{~mm} / \mathrm{rev}$. with composite desirability $=0.95$. Figure 7 shows the optimization plot of Ra. These optimum conditions were run to validate the regression and optimization process, and the results are summarized in
Table 8 . The small $\%$ error $(\leq 5 \%)$ proves the match between experimental and model predicted values.

\section{Conclusions}

In this research, a relation between the experiments done in closed ideal lab conditions and the actual manufacturing processes in workshops is investigated. Under real working conditions, uncontrolled parameters may interfere with 


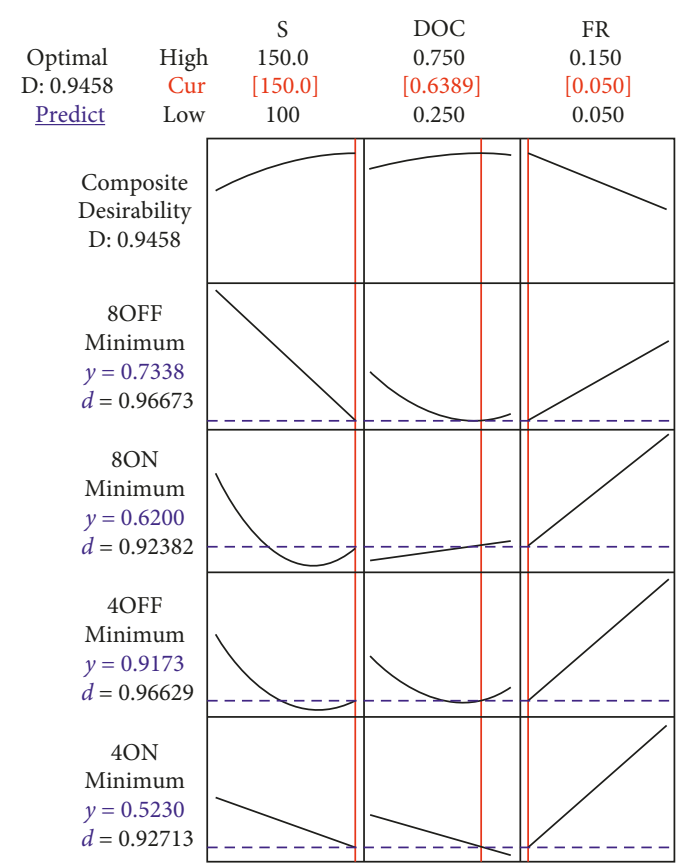

Figure 7: Optimization plot for Ra under different combinations of noise factors.

TABLE 8: Measured and expected values of Ra under optimum conditions for all combinations of noise factors.

\begin{tabular}{lccccccc}
\hline Test run & $\begin{array}{c}\text { Surface speed } \\
(\mathrm{m} / \mathrm{min})\end{array}$ & $\begin{array}{c}\text { Depth of } \\
\text { cut }(\mathrm{mm})\end{array}$ & $\begin{array}{c}\text { Feed rate } \\
(\mathrm{mm} / \mathrm{rev})\end{array}$ & $\begin{array}{c}\text { Tool nose } \\
\text { radius }(\mathrm{mm})\end{array}$ & Coolant & $\begin{array}{c}\text { Measured } \\
\text { Ra }(\mu \mathrm{m})\end{array}$ & $\begin{array}{c}\text { Predicted } \\
\text { Ra }(\mu \mathrm{m})\end{array}$ \\
\hline 1 & 150 & 0.64 & 0.05 & 0.4 & On & 0.509 & 0.522 \\
2 & 0.62 & 0.4 & Off & 0.964 & 0.915 \\
3 & 150 & 0.64 & 0.05 & 0.8 & On & 0.591 & 0.622 \\
4 & 150 & 0.64 & 0.05 & 0.8 & Off & 0.766 & 0.737 \\
\hline
\end{tabular}

machining requirements inducing lower controlled product quality. Two noise parameters have been considered to evaluate their effects on the processing quality, and optimal control parameters have been determined to minimize their interference with the final quality requirement.

Taguchi robust design was used to minimize the effect of two noise factors: tool nose radius and coolant operation, on the produced $\mathrm{Ra}$. ANOVA results showed that all investigated control and noise factors had significant effects on the output $\mathrm{Ra}$ proving the importance of this investigation. Regression analysis and composite desirability function were used to select the optimum combination of control factors that will minimize the expected $\mathrm{Ra}$ despite the effects of the noise factors. A predictive model has been developed to determine the optimum combination of control factors for different configurations of noise factors as illustrated in Tables 7 and 8 . The results show low prediction errors $(\leq 5 \%)$ when compared to real experimental tests. An optimum combination of $150 \mathrm{~m} / \mathrm{min}$ surface speed, $0.64 \mathrm{~mm}$ depth of cut, and $0.05 \mathrm{~mm} / \mathrm{rev}$ feed rate is used in case of uncertain combination of tool nose radius and coolant condition.

\section{Data Availability}

The data used to support the findings of this study are available from the corresponding author upon request.

\section{Conflicts of Interest}

The authors declare no conflicts of interest.

\section{Acknowledgments}

The authors extend their appreciation to the Deanship of Scientific Research at King Saud University for funding this work through research group no. RG-1439-020.

\section{References}

[1] D. Deepak and B. Rajendra, "Optimization of machining parameters for turning of Al6061 using robust design principle to minimize the surface roughness," Procedia Technology, vol. 24, pp. 372-378, 2016.

[2] J. Z. Zhang, J. C. Chen, and E. D. Kirby, "Surface roughness optimization in an end-milling operation using the Taguchi 
design method," Journal of Materials Processing Technology, vol. 184, no. 1-3, pp. 233-239, 2007.

[3] A. Qasim, S. Nisar, A. Shah, M. S. Khalid, and M. A. Sheikh, "Optimization of process parameters for machining of AISI1045 steel using Taguchi design and ANOVA," Simulation Modelling Practice and Theory, vol. 59, pp. 36-51, 2015.

[4] A. Bhattacharya, S. Das, P. Majumder, and A. Batish, "Estimating the effect of cutting parameters on surface finish and power consumption during high speed machining of AISI 1045 steel using Taguchi design and ANOVA," Production Engineering, vol. 3, no. 1, pp. 31-40, 2009.

[5] C. Moganapriya, R. Rajasekar, K. Ponappa, R. Venkatesh, and $\mathrm{S}$. Jeromec, "Influence of coating material and cutting parameters on surface roughness and material removal rate in turning process using Taguchi method," Materials Today: Proceedings, vol. 5, no. 2, pp. 8532-8538, 2018.

[6] R. M. Mazarbhuiya, P. K. Choudhury, and P. K. Patowari, “An experimental study on parametric optimization for material removal rate and surface roughness on EDM by using Taguchi method," Materials Today: Proceedings, vol. 5, no. 2, pp. 4621-4628, 2018.

[7] D. Manivel and R. Gandhinathan, "Optimization of surface roughness and tool wear in hard turning of austempered ductile iron (grade 3) using Taguchi method," Measurement, vol. 93, pp. 108-116, 2016.

[8] M. Nalbant, H. Gökkaya, and G. Sur, "Application of Taguchi method in the optimization of cutting parameters for surface roughness in turning," Materials and Design, vol. 28, no. 4, pp. 1379-1385, 2007.

[9] I. Asiltürk and H. Akkuş, "Determining the effect of cutting parameters on surface roughness in hard turning using the Taguchi method," Measurement, vol. 44, no. 9, pp. 1697-1704, 2011.

[10] Y. K. Hwang and C. M. Lee, "Surface roughness and cutting force prediction in MQL and wet turning process of AISI 1045 using design of experiments," Journal of Mechanical Science and Technology, vol. 24, no. 8, pp. 1669-1677, 2010.

[11] A. T. Abbas, K. Hamza, M. F. Aly, and E. A. Al-Bahkali, "Multiobjective optimization of turning cutting parameters for J-steel material," Advances in Materials Science and Engineering, vol. 2016, Article ID 6429160, 8 pages, 2016.

[12] E. A. Al Bahkali, A. E. Ragab, E. A. El Danaf, and A. T. Abbas, "An investigation of optimum cutting conditions in turning nodular cast iron using carbide inserts with different nose radius," Proceedings of the Institution of Mechanical Engineers, Part B: Journal of Engineering Manufacture, vol. 230, no. 9, pp. 1584-1591, 2016.

[13] K. S. Kim, K. T. Jung, J. M. Kim, J. P. Hong, and S. I. Kim, "Taguchi robust optimum design for reducing the cogging torque of EPS motors considering magnetic unbalance caused by manufacturing tolerances of PM," IET Electric Power Applications, vol. 10, no. 9, pp. 909-915, 2016.

[14] A. E. Ragab, "Multi-objective optimization of profile accuracy in two point incremental forming using Taguchi-based grey relation analysis," International Journal of Collaborative Enterprise, vol. 6, no. 1, pp. 49-65, 2018.

[15] A. T. Abbas, A. E. Ragab, E. A. Al Bahkali, and E. A. El Danaf, "Optimizing cutting conditions for minimum surface roughness in face milling of high strength steel using carbide inserts," Advances in Materials Science and Engineering, vol. 2016, Article ID 7372132, 14 pages, 2016. 


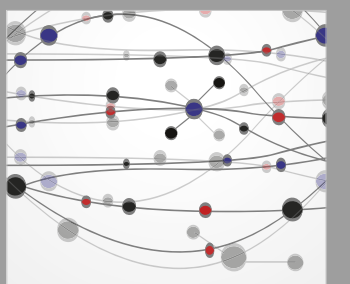

The Scientific World Journal
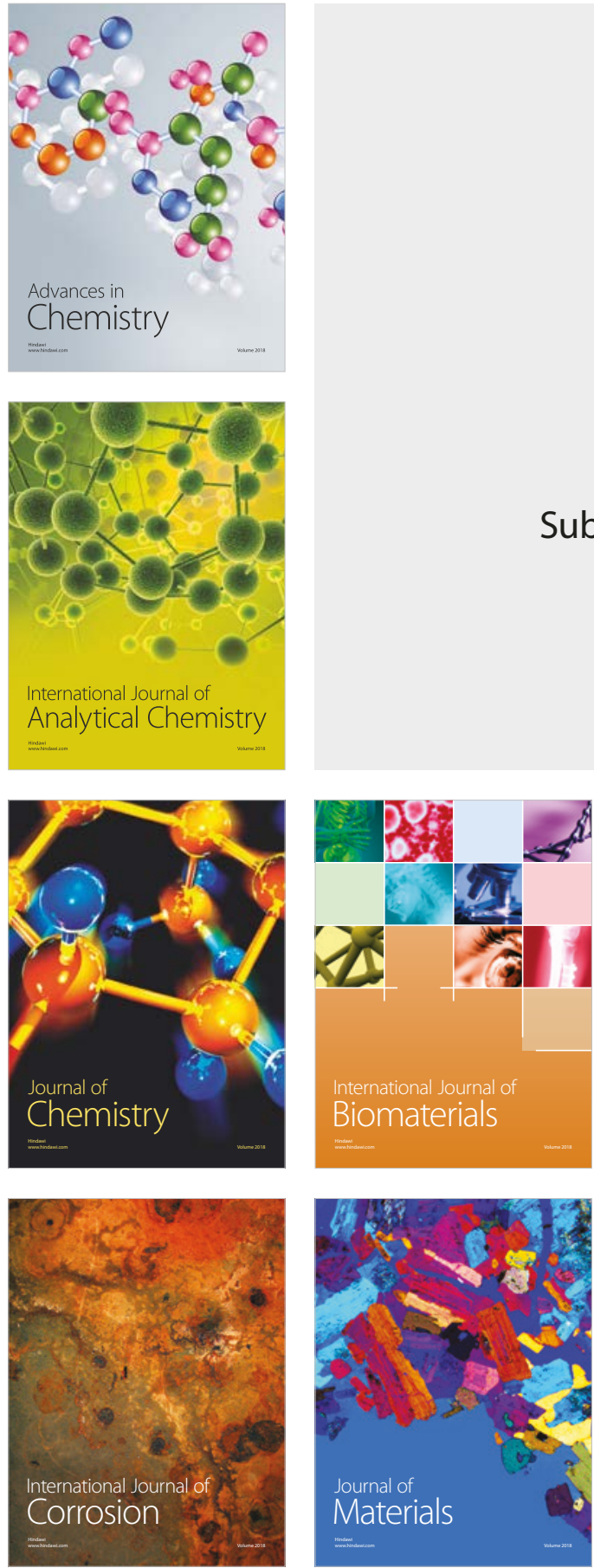

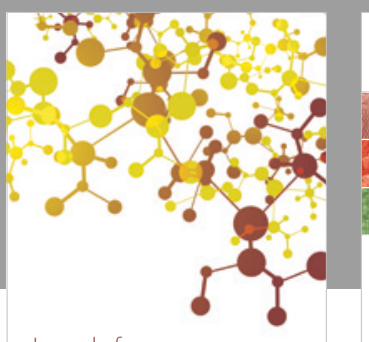

Journal of

Applied Chemistry
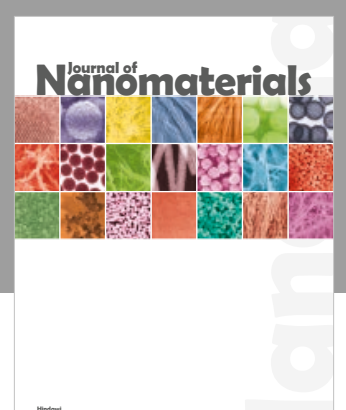

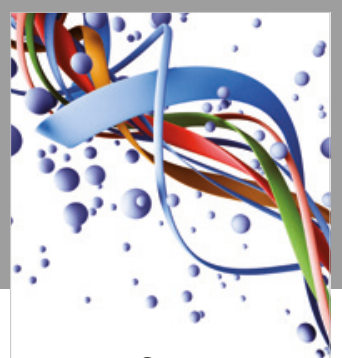

Scientifica

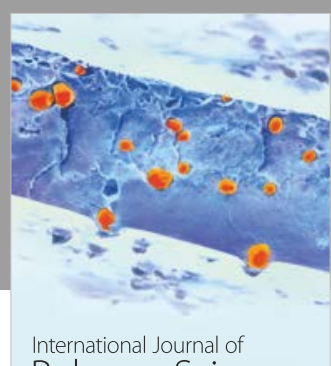

Polymer Science

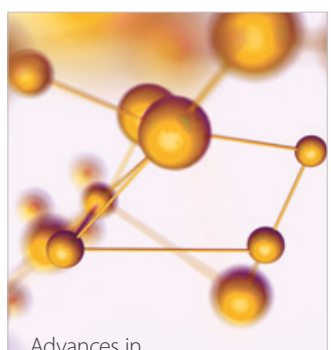

Physical Chemistry
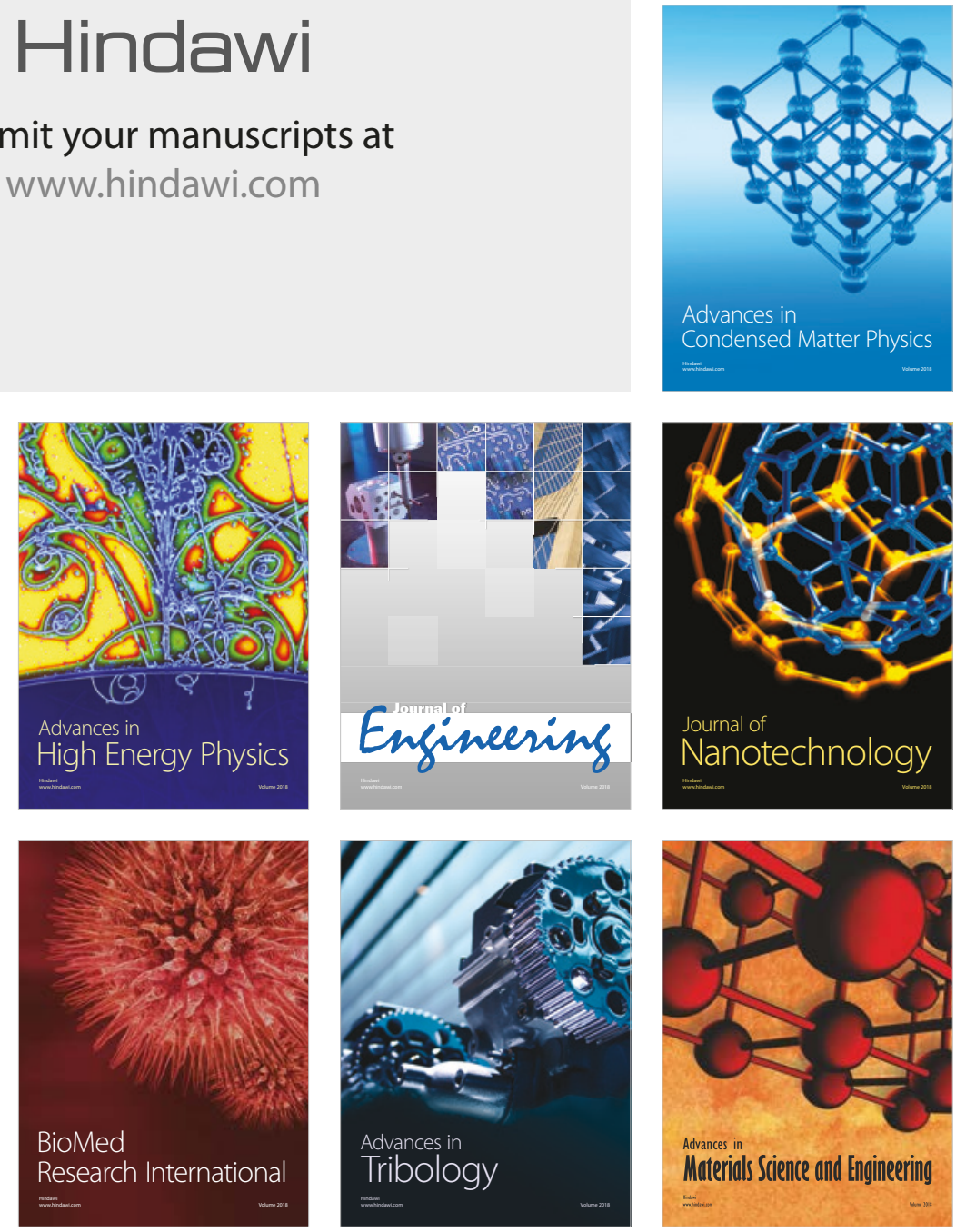